\title{
Mechanical circulatory support in acute cardiogenic shock
}

\section{Mubashar H Khan, Brian J Corbett and Steven M Hollenberg*}

\author{
Address: Cooper University Hospital, One Cooper Plaza, Camden, NJ 08103, USA \\ *Corresponding author: Steven M Hollenberg (hollenberg-steven@cooperhealth.edu) \\ Fl000Prime Reports 2014, 6:91 (doi:10.12703/P6-91) \\ All Fl000Prime Reports articles are distributed under the terms of the Creative Commons Attribution-Non Commercial License \\ (http://creativecommons.org/licenses/by-nc/3.0/legalcode), which permits non-commercial use, distribution, and reproduction in any medium, \\ provided the original work is properly cited. \\ The electronic version of this article is the complete one and can be found at: http://f $1000 . c o m / p r i m e /$ reports $/ \mathrm{m} / 6 / 9$ |
}

\begin{abstract}
Cardiogenic shock complicates about $5 \%$ to $8 \%$ of all admissions for acute myocardial infarction, and despite advancement in treatment over the past 50 years, mortality remains unacceptably high. Management with vasoactive agents after revascularization can have its limitations and thus mechanical circulatory support is often initiated. Intra-aortic balloon pumps (IABPs) are the devices most commonly used worldwide. IABPs appeared to improve mortality when used along with fibrinolytic therapy but may not when used along with percutaneous coronary interventions. Extracorporeal membrane oxygenation (ECMO) is utilized in the setting of worsening tissue perfusion despite inotropes and IABP utilization. Although retrospective studies show some mortality benefit, randomized prospective studies have not yet demonstrated ECMO to be advantageous either with or without IABP. Percutaneous left ventricular

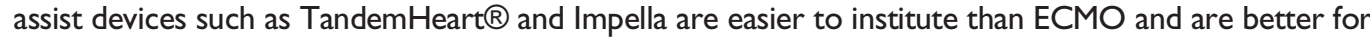
hemodynamics compared with the IABP but also have not yet shown a mortality benefit. More randomized studies are needed to define the most appropriate role of the various mechanical support devices in cardiogenic shock.
\end{abstract}

\section{Introduction}

Cardiogenic shock is a physiologic state in which end-organ tissue hypoperfusion is a result of cardiac dysfunction, where the heart is unable to maintain adequate cardiac output despite adequate intravascular volume [1]. It complicates about $5 \%$ to $8 \%$ of all ST segment elevation myocardial infarctions (STEMIs) as well as other primary cardiac abnormalities including myocardial disease, valvular heart disease, and congenital heart disease [2]. Despite many advances in the early diagnosis, treatment, and management of cardiogenic shock, mortality remains unacceptably high $[2,3]$. Recent advances in mechanical cardiac support (MCS) of the failing ventricle present the potential for improvements in outcome. The aim of this review is to assess the role of MCS in acute cardiogenic shock.

Cardiogenic shock manifests clinically as hypotension without hypovolemia with signs of poor tissue perfusion such as oliguria, cyanosis, cool extremities, and altered mentation [1]. A more concrete hemodynamic definition consists of persistent hypotension (systolic blood pressure of less than 80 to $90 \mathrm{~mm} \mathrm{Hg}$ or mean arterial pressure $30 \mathrm{~mm} \mathrm{Hg}$ lower than baseline) with severe reduction in cardiac index (less than $1.8 \mathrm{~L} / \mathrm{min}$ per $\mathrm{m}^{2}$ without support or less than 2.0 to $2.2 \mathrm{~L} / \mathrm{min}$ per $\mathrm{m}^{2}$ with support) and adequate or elevated filling pressure (for example, left ventricular [LV] end-diastolic pressure of less than $18 \mathrm{~mm} \mathrm{Hg}$ or right ventricular end-diastolic pressure of less than 10 to $15 \mathrm{~mm} \mathrm{Hg}$ ) [4].

The most common cause of cardiogenic shock is acute myocardial infarction (MI). Myocardial ischemia leads to both systolic and diastolic compromise; the resulting myocardial dysfunction can worsen ischemia, creating a downward spiral. When a critical mass of myocardium is affected, stroke volume and cardiac output decrease, leading to hypotension. This in turn lowers coronary perfusion pressure, potentiating ischemia, and induces compensatory vasoconstriction to maintain blood pressure, which can worsen cardiac dysfunction. If this cycle is not reversed, death is the result. 
Coronary revascularization is the mainstay of therapy for cardiogenic shock caused by myocardial infarction, but after reperfusion, areas of the myocardium may have myocardial stunning, post-ischemic dysfunction that persists despite restoration of normal blood flow. Other myocardial segments may have persistently impaired function at rest because of severely reduced coronary blood flow, which is referred to as hibernating myocardium. These areas may improve over time with revascularization. Regardless of the mechanism, the concept that areas of the myocardium may have reversible dysfunction and may recover over time provides a strong rationale for supportive hemodynamic therapies in cardiogenic shock.

To address the hemodynamic abnormalities in cardiogenic shock, initial therapy involves careful infusion of fluids, as patients with acute MI can have intravascular fluid loss consequent to diaphoresis or vomiting and may be either absolutely or relatively hypovolemic. If shock is persistent despite fluid resuscitation, initial therapy is pharmacologic, with a delicate balance of inotropic or vasopressor agents or both [5]. Dobutamine, a $\beta_{1}$ adrenoreceptor agonist, is often the first inotropic agent utilized, as it can enhance contractility and can provide support until stunned or reperfused myocardium recovers [6]. Owing to dobutamine's arrhythmogenic properties, other inotropic agents such as milrinone can be considered, but these agents can cause significant hypotension and have not been shown to improve mortality [7]. In patients requiring vasopressors to support systemic blood pressure, norepinephrine is preferred to dopamine [8]. Use of inotropes and vasopressors in cardiogenic shock increases myocardial oxygen demand, and studies of their efficacy have been small and have not necessarily demonstrated that their use improves mortality. Mechanical circulatory support devices can provide substantial cardiovascular support without potentiating myocardial ischemia and may also decrease myocardial oxygen demand, which renders their use theoretically attractive.

\section{Intra-aortic balloon pump counterpulsation}

Counterpulsation with an IABP is the oldest and most commonly used mechanical circulatory support mechanism worldwide [9]. The concept of counterpulsation was devised based on the fact that coronary flow occurs during diastole and thus diastolic augmentation might improve coronary artery flow, improve systemic blood pressure, and decrease myocardial oxygen demand [10]. The IABP was pioneered in the early 1960 s by Dr. Adrian Kantrowitz at Maimonides Hospital in Brooklyn, NY. His first patient, described in 1968, was a 45 -year-old woman in cardiogenic shock, who was supported with IABP for 7 hours, survived, and was subsequently discharged [11]. Over 3 million patients have been treated with IABPs since the 1980s, when they came into general use [12].

The IABP consists of a balloon catheter and a pump console that inflates the balloon with helium at the end of systole. The catheter is commonly placed in the cardiac catheterization lab under fluoroscopic guidance but may also be placed at bedside with confirmation on chest X-ray, with the proximal tip distal to the origin of the left subclavian artery and the distal aspect of the balloon proximal to the renal artery (Figure 1). Inflation timing is based on electrocardiography or arterial pressure waveform or more commonly now on programmed algorithms that determine aortic valve closure in the context of the possibility of arrhythmias [13].

The hemodynamic advantages with balloon counterpulsation include the following: an increase in stroke volume and cardiac output; an increase in systemic blood pressure with increased coronary blood flow; a decrease in LV wall stress and myocardial oxygen demand; a reduction in LV preload, LV end-diastolic pressure, and pulmonary capillary wedge pressure; and a mild improvement in microcirculatory flow [14].

Studies conducted to test the clinical effectiveness of IABP counterpulsation have had varied endpoints. Prior to the age of coronary revascularization in the setting of myocardial infarction, IABPs were not shown to modify infarct size or alter morbidity or mortality when compared with standard therapy in cardiogenic shock, likely because IABPs do not increase flow distal to a critical coronary stenosis $[15,16]$. Not until coronary reperfusion therapy was common did data suggest that IABPs might improve mortality, possibly by supporting patients through a period of myocardial stunning. In 1997, an analysis of patients in the Global Utilization of Streptokinase and Tissue Plasminogen Activator for Occluded Arteries (GUSTO-1) trial showed a trend toward lower 30-day and 1-year mortality in patients treated with an IABP and fibrinolytic therapy compared with fibrinolytic therapy alone [17]. Another retrospective study showed that combined therapy with IABP and fibrinolytics improved in-hospital and 1-year survival $(67 \%$ versus $32 \%, P=0.019)$ versus fibrinolytic therapy alone [18]. The Should We Emergently Revascularize Occluded Coronaries in Cardiogenic Shock? (SHOCK) trial registry controlled for confounding by reperfusion therapy and showed that in-hospital mortality was lower in patients supported with IABP (lytics + IABP, 47\%; IABP only, 52\%; lytics only, 63\%; no lytics, no IABP, 77\%; $P<0.0001$ ) [19]. Comparable results were found in an analysis of 23,000 patients in the 


\section{Figure I. Intra-aortic balloon pump}

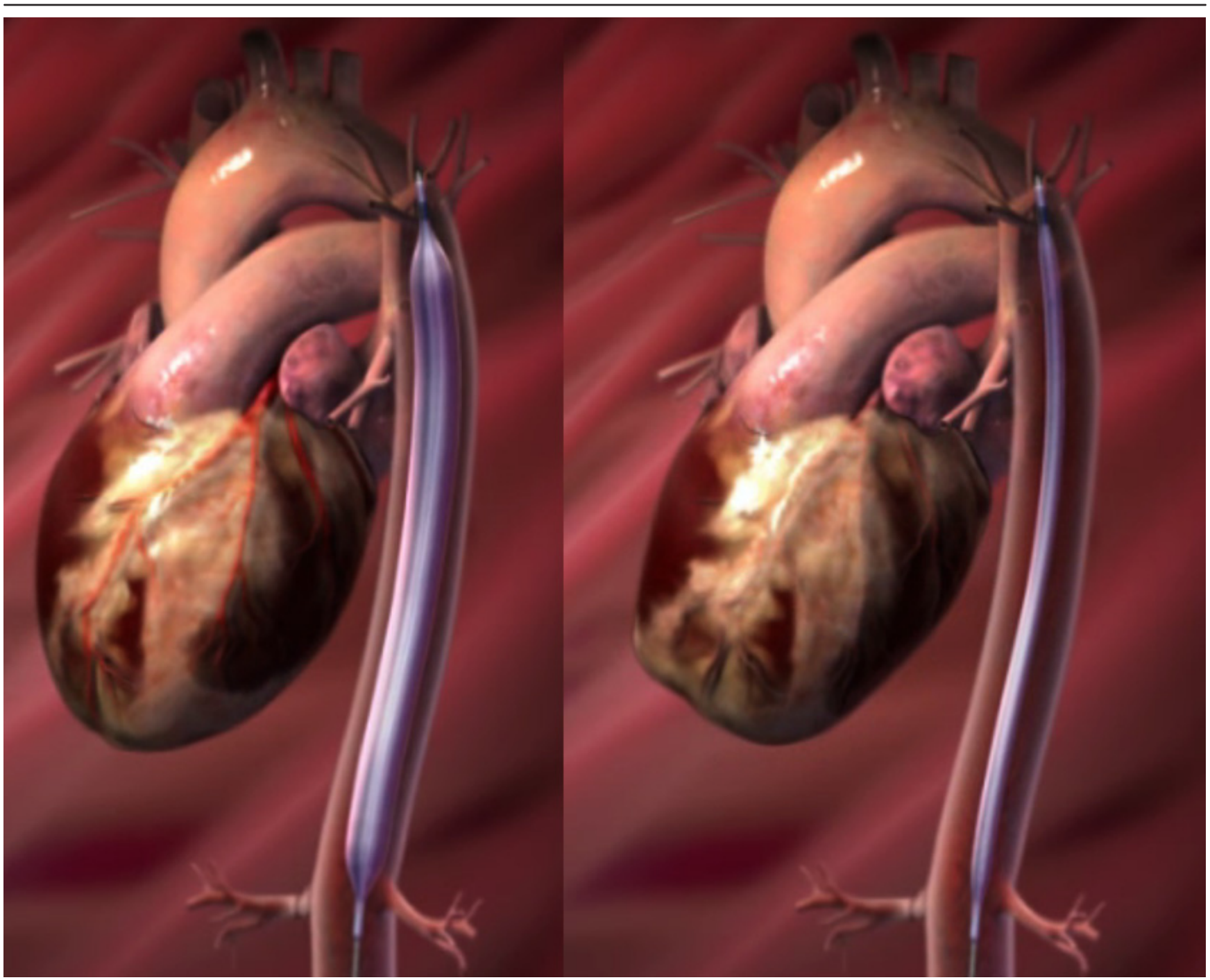

A computer-controlled mechanism inflates a cylindrical polyethylene balloon with helium during diastole (left) and then actively deflates the balloon in systol (right). The tip of the balloon should be approximately $2 \mathrm{~cm}$ from the left subclavian artery. Image provided with permission from MAQUET Cardiac Assist, Datascope Corp.

National Registry of Myocardial Infarction 2 (NRMI-2), where IABP plus fibrinolytic therapy decreased the odds of death by $18 \%$ (odds ratio $0.82,95 \%$ confidence interval [CI] 0.72 to 0.93 ) [20].

The mortality benefit conferred by IABP counterpulsation in patients treated with fibrinolytics is evident, but when it comes to percutaneous coronary intervention (PCI), studies have been mixed. Use of IABP in the NRMI-2 study was not associated with any mortality benefit in patients treated with primary angioplasty (45\% versus $47 \%$ ) [20]. A meta-analysis showed that IABP was associated with an $18 \%$ (95\% CI $16 \%$ to $20 \%$;
$P<0.0001)$ decrease in 30-day mortality in patients treated with fibrinolysis but only a $6 \%$ decrease $(95 \%$ CI $3 \%$ to $10 \% ; P<0.0008)$ in patients treated with primary PCI [21]. It should be recognized that observational data concerning IABP therapy in the setting of cardiogenic shock are importantly hampered by bias and confounding [21].

The IABP-SHOCK trial randomly assigned 45 patients with an acute myocardial infarction and cardiogenic shock to IABP + PCI versus PCI alone and was not powered for mortality benefit but did not show either a decrease in mortality or a significant improvement in multi-organ dysfunction score with the addition of IABP 
counterpulsation to standard therapy [22]. The IABPSHOCK II study, a much larger prospective, randomized, open-label, multicenter trial enrolling 600 patients with cardiogenic shock complicating acute myocardial infarction, randomly assigned patients to an IABP group or a non-IABP group. There was no significant difference in the primary endpoint of 30-day all-cause mortality (39.7\% versus $41.3 \% ; P=0.69$ ) nor was there a significant difference in any of the subgroups. Secondary safety endpoints such as major bleeding, peripheral ischemic complications, sepsis, and stroke did not differ between the two groups [23]. Subsequent follow-up showed no 12-month mortality benefit with the use of IABP [24]. The decision to use an IABP based upon this study may still be up to the clinician as some randomly assigned patients received an IABP when they were hemodynamically stable and might not have been expected to derive great benefit. In addition, $10 \%$ of patients in the control group crossed over to IABP therapy.

Despite the lack of a demonstrated mortality benefit in randomized control trials, it is the opinion of the authors that IABP counterpulsation still has a significant role for the stabilization of patients with cardiogenic shock. Owing to its widespread availability, safety, lower cost compared with other support devices, and ease of placement in many health-care facilities, IABP counterpulsation can be utilized as adjunctive therapy in cardiogenic shock. Insertion of an IABP for patients with hemodynamic instability was given a class IIa recommendation in the American College of Cardiology/American Heart Association (ACC/AHA) guidelines and a class IIb recommendation by the European Society of Cardiology (ESC) (Table 1) $[25,26]$. Whether its use will be superseded by other mechanical circulatory support devices remains to be seen.

\section{Extracorporeal membrane oxygenation}

The mechanism behind ECMO involves draining blood from the venous system, oxygenating it through an oxygenator, and returning this oxygenated blood into the systemic circulation by a centrifugal pump. Artificial oxygenation and perfusion support was used for the first successful open heart operation by Gibbon in 1953 [27]. ECMO was subsequently used predominantly in a pediatric population $[28,29]$. ECMO was used outside of these settings in 1972 when partial veno-arterial (VA) perfusion with peripheral cannulation, with a Bramson membrane heart-lung machine, was initiated and continued for 75 hours on a 24-year-old male with respiratory failure 4 days after repair of a transected thoracic aorta [30].

VA ECMO can be delivered centrally, which involves cannulation of the right atrium and aorta [31], or peripherally with femoral artery and venous cannulation. Although peripheral VA ECMO can reduce LV preload, it can in turn lead to increased ventricular wall tension due to retrograde flow from the femoral arterial cannulation and thus needs to be monitored more closely as opposed to central VA ECMO (Figure 2). Other potential ECMO complications include a risk of bleeding (upwards of 50\%) as well as clotting abnormalities, with a stroke incidence as high as $10 \%$.

Initial survival from ECMO was reported to be $25 \%$ to $30 \%$, although the indication for ECMO varied from post-cardiotomy LV failure to cardiogenic shock [32-34]. Whereas earlier studies showed improved survival with complicated PCI, a 2008 study did not show remarkably improved survival with ECMO after post-cardiotomy cardiogenic shock, with survival at about 40\% [33]. In a recent retrospective study, the addition of ECMO to patients in cardiogenic shock improved survival at

Table I. Guideline recommendations in cardiogenic shock $[25,26]$

\begin{tabular}{|c|c|c|c|c|}
\hline \multirow{2}{*}{$\begin{array}{l}\text { Assist device } \\
\text { IABP }\end{array}$} & \multicolumn{2}{|c|}{ ACC/AHA/SCAI guidelines } & \multicolumn{2}{|c|}{ ESC/EACTS guidelines } \\
\hline & Class Ila & $\begin{array}{l}\text { A hemodynamic support device } \\
\text { is recommended for patients with } \\
\text { cardiogenic shock after STEMI } \\
\text { who do not quickly stabilize } \\
\text { with pharmacological therapy. }\end{array}$ & Class Ilb & $\begin{array}{l}\text { IABP insertion is recommended in } \\
\text { patients with hemodynamic instability } \\
\text { (particularly those in cardiogenic shock } \\
\text { and with mechanical complications). }\end{array}$ \\
\hline ECMO & No recommendation & No recommendation & No recommendation & $\begin{array}{l}\text { ECMO implantation should be } \\
\text { considered for temporary support in } \\
\text { patients with acute heart failure with } \\
\text { potential for functional recovery } \\
\text { following revascularization. }\end{array}$ \\
\hline TandemHeart ${ }^{\circledR}$ & Class Ilb & Same as IABP & Class Ilb & $\begin{array}{l}\text { Routine use of percutaneous centrifugal } \\
\text { pumps is not recommended. }\end{array}$ \\
\hline Impella & Class Illb & Same as IABP & No recommendation & No recommendation \\
\hline
\end{tabular}

Abbreviations: ACC/AHA, American College of Cardiology/American Heart Association; EACTS, European Association for Cardio-Thoracic Surgery; ECMO, extracorporeal membrane oxygenation; ESC, European Society of Cardiology; IABP, intra-aortic balloon pump; SCAI, Society for Cardiovascular Angiography and Interventions; STEMI, ST segment elevation myocardial infarction. 


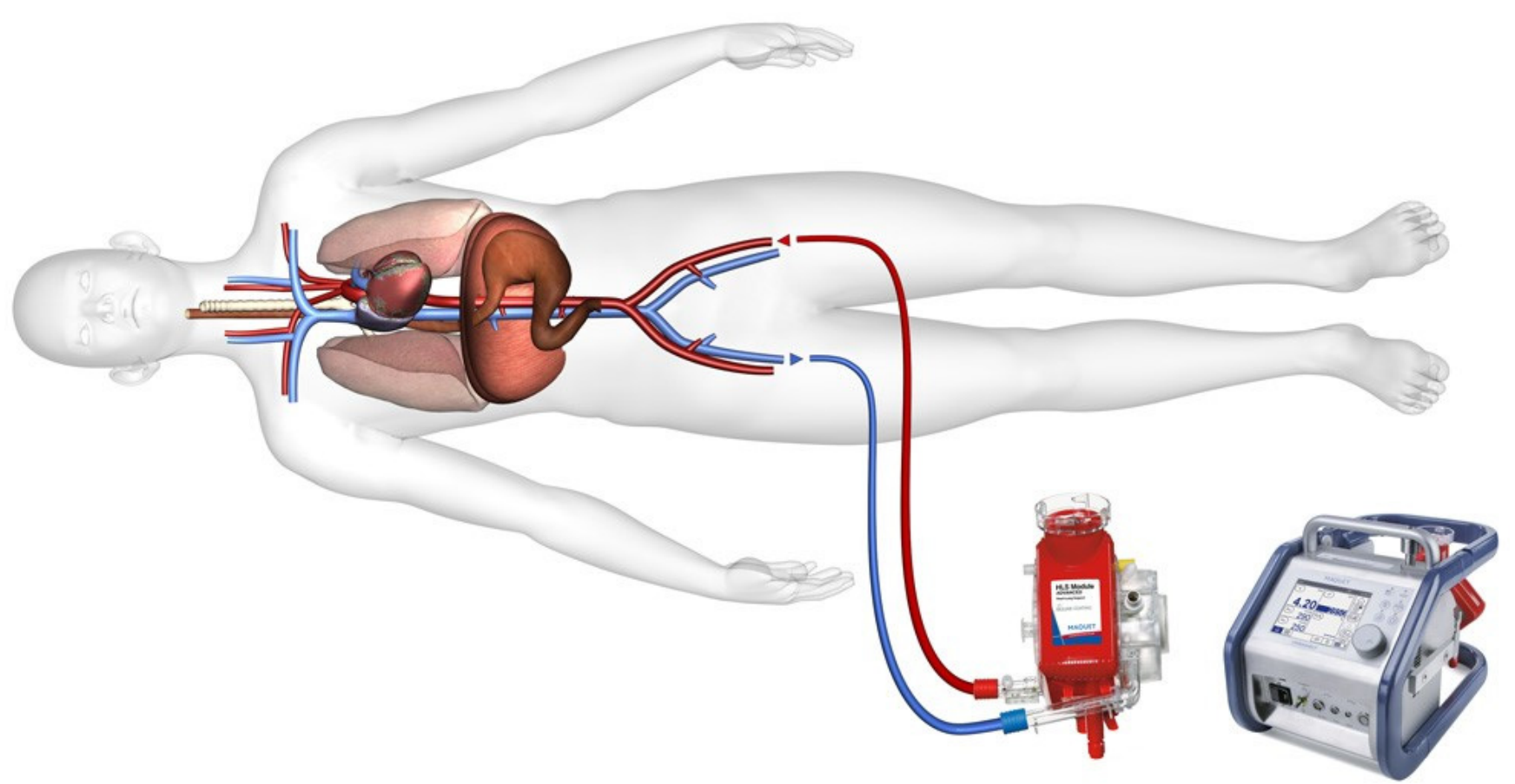

A catheter is placed in a central vein from which a mechanical pump draws out venous blood and passes it into an oxygenator. This oxygenated blood is then warmed or cooled and returned to the arterial system. Images provided with permission from MAQUET Cardiac Assist, Datascope Corp.

discharge and at 1 year (63\% versus 24\%; $P=0.001$ ) [35]. This study, however, was small and potentially confounded since the comparison group was not contemporaneous.

Approximately 13,000 patients have been treated with ECMO, and the survival to discharge rate was 39\% in adults when ECMO was used for cardiac support [36]. When to initiate ECMO in cardiogenic shock is difficult to assess, and the scarcity of patients in randomized trials may explain why there are still no consensus recommendations by the ACC/AHA [25]. The European STEMI guidelines give a class IIb recommendation for the use of ECMO in patients with refractory cardiogenic shock [26]. ECMO may be considered in the context of refractory cardiogenic shock with continued endorgan tissue hypoperfusion and as a bridge to emergent transplantation or ventricular assist device (VAD) placement.

\section{Ventricular assist devices}

VADs are mechanical circulatory support devices that are designed to assist/mimic a normally functioning heart. DeBakey described the first device in the late 1960s: "A gas-energized, synchronized, hemispherical pump, of Dacron $\AA$-reinforced Silastic $®$, has been used effectively to relieve the strain on the failing left ventricle during the early recuperative period after open heart surgery" [37]. The pump propels blood forward from the left ventricle (left ventricular assist device [LVAD]) or the right ventricle (right ventricular assist device [RVAD]) or both (biventricular assist device [BIVAD]). The pump technology was originally pulsatile, which attempted to mimic the normal function of the heart. Often a vent outside the body was required to store blood between the pulsations. Current technology provides continuous flow, using either centrifugal pumps or axial flow pumps. Both are more durable and smaller in design than pulsatile pumps, using electric currents in the coil to spin magnetic rotors as much as 15,000 times per minute and expel blood forward [38]. VADs can be used temporarily with the intent that they are a bridge to recovery or a bridge to decision. More recently, implantable VADs have been employed as destination therapy as opposed to being only a bridge to transplant.

In the context of acute cardiogenic shock, percutaneous LVADs (pLVADs) have recently been developed and 
implanted temporarily as a bridge to recovery or decision. One of the main advantages for VADs is their ability to operate independent of a patient's intrinsic cardiac rhythm or output and thus provide more cardiac support via increased systemic flow [39].

\section{TandemHeart $\circledast$}

The TandemHeart ${ }^{\circledR}$ (CardiacAssist, Pittsburgh, PA, USA) is an extracorporeal pLVAD device with a centrifugal pump first conceived as short-term support for a patient in cardiogenic shock by researchers at Allegheny General
Hospital (Pittsburgh, PA, USA). It consists of a cannula that is inserted in the femoral vein and advanced across the atrial septum into the left atrium where oxygenated blood is obtained (Figure 3). This oxygenated blood is then aspirated and pumped into one or both femoral arteries at a rate of $4.0 \mathrm{~L} / \mathrm{min}$ [40]. By unloading the left ventricle, it reduces pulmonary capillary wedge pressure and LV preload and subsequently improves peripheral tissue perfusion, despite a mild increase in afterload due to the pumping of blood back into the femoral arteries (Table 2). The TandemHeart ${ }^{\circledR}$ is usually placed to allow

Figure 3. TandemHeart $\circledast$

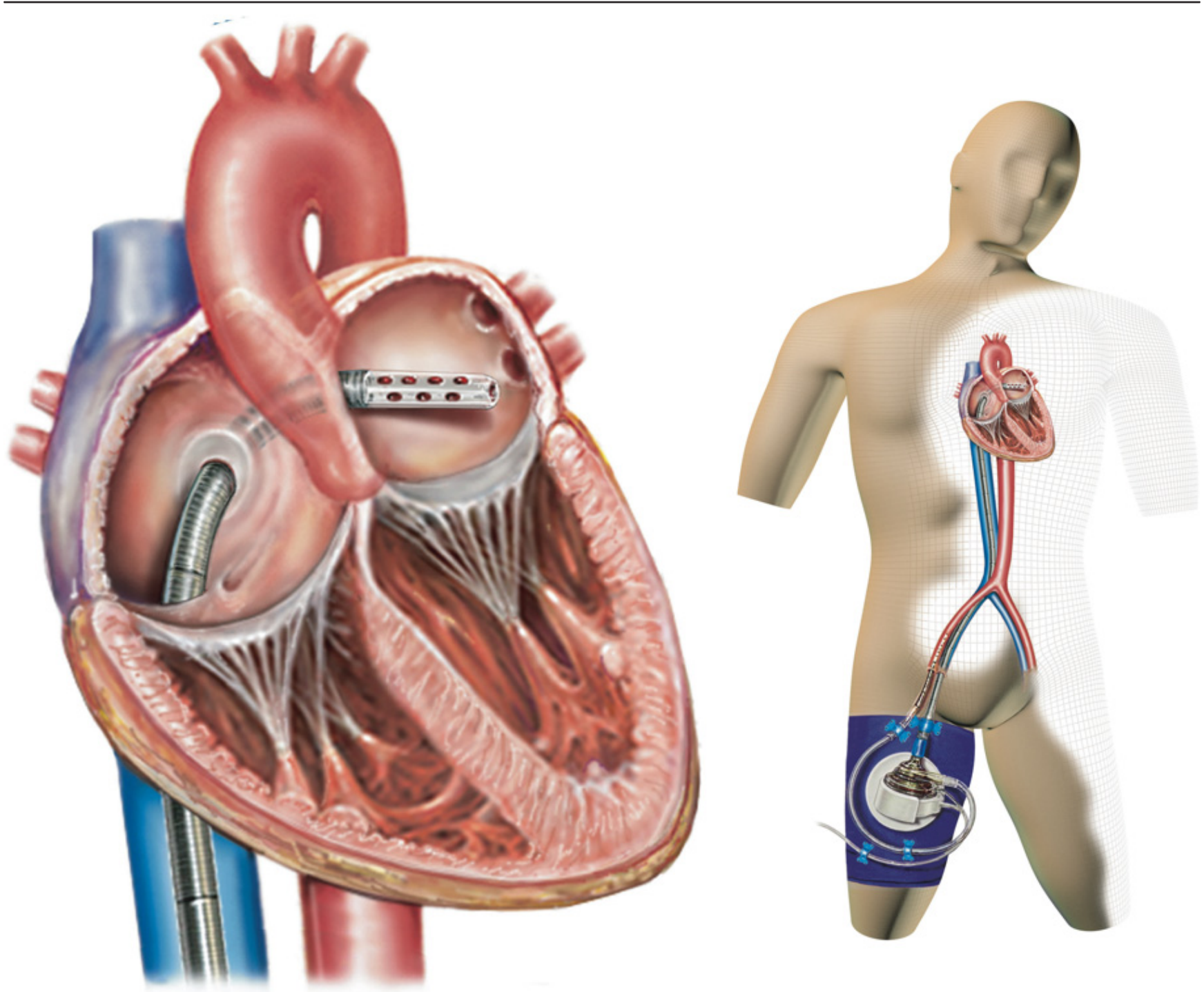

The TandemHeart $®$ transseptal cannula withdraws oxygenated blood from the left atrium to bypass the left ventricle, the target for work reduction. The centrifugal pump provides up to $5 \mathrm{~L} / \mathrm{min}$ of forward and uniform flow in a percutaneous configuration as well as full pressure support. The arterial cannula returns oxygenated blood to the femoral artery, completing the extracorporeal circuit. Images provided with permission from CardiacAssist (Pittsburgh, PA, USA). 
Table 2. Hemodynamic effects of mechanical circulatory support devices [50-53]

\begin{tabular}{|c|c|c|c|c|}
\hline & IABP & ECMO & TandemHeart $\circledR$ & Impella \\
\hline PAOP & Slightly $\downarrow$ & $\downarrow$ & $\downarrow$ & $\downarrow$ \\
\hline LV preload & Slightly $\downarrow$ & $\downarrow^{a}$ & $\downarrow$ & $\downarrow$ \\
\hline Afterload & Slightly $\downarrow$ & $\uparrow$ & $\uparrow$ & $\leftrightarrow$ \\
\hline Mean Arterial Pressure & $\uparrow$ & $\uparrow$ & $\uparrow \uparrow$ & $\uparrow \uparrow$ \\
\hline LV stroke volume & Slightly $\uparrow$ & $\downarrow$ & $\downarrow$ & $\downarrow$ \\
\hline Cardiac Output & Slightly $\uparrow$ & $\uparrow$ & $\uparrow \uparrow$ & $\uparrow \uparrow$ \\
\hline Coronary perfusion & Slightly $\uparrow$ & - & $\uparrow$ & $\uparrow$ \\
\hline Oxygen Consumption & Slightly $\downarrow$ & $\downarrow$ & $\downarrow$ & $\downarrow$ \\
\hline Peripheral tissue perfusion & $\leftrightarrow$ & $\uparrow$ & $\uparrow$ & $\uparrow$ \\
\hline
\end{tabular}

${ }^{a}$ In LV failure, ECMO reduces LV preload. In other settings, the effect of ECMO on LV preload can be variable. ECMO flow rates can also affect LV preload. Key: $\downarrow=$ reduced, $\uparrow=$ increased or improved, $\uparrow \uparrow=$ largely increased, $\leftrightarrow=$ neutral.

Abbreviations: ECMO, extracorporeal membrane oxygenation; IABP, intra-aortic balloon pump; LV, left ventricular; PAOP, pulmonary artery occlusion pressure.

support for a few hours to days, but its use has been reported up to 14 days.

The TandemHeart ${ }^{\circledR}$ was shown in a randomized 2005 trial to improve cardiac power index, as well as other hemodynamic and metabolic variables, compared with IABP counterpulsation, in patients with an acute MI and intended PCI and cardiogenic shock [41]. Similar hemodynamic improvement was shown by the TandemHeart ${ }^{\circledR}$ Investigators Group in 2006; TandemHeart ${ }^{\circledR}$ percutaneous VAD (pVAD), compared with IABP counterpulsation, achieved significantly greater increases in cardiac index and mean arterial blood pressure and significantly greater decreases in pulmonary capillary wedge pressure [42]. Neither study, however, showed a 30-day mortality benefit with the TandemHeart ${ }^{\circledR}[41,42]$. In 2011, another study showed that TandemHeart ${ }^{\circledR}$ placed in patients with severe cardiogenic shock rapidly reversed the terminal hemodynamic compromise seen in patients with severe cardiogenic shock refractory to IABP and vasopressor support; cardiac index improved from a median of 0.52 to $3.0 \mathrm{~L} / \mathrm{min}$ per $\mathrm{m}^{2}(P<0.001)[43]$.

The ACC/AHA guidelines give a class IIb recommendation for LVADs in the context of cardiogenic shock in ST elevation MI [25]. Despite significantly improved hemodynamic parameters compared with IABP counterpulsation, no study has yet shown a mortality benefit. In addition, the complexity of inserting a large-bore catheter (21 French $[\mathrm{Fr}]$ ) as well as a transseptal puncture requires specialized skills and may not be able to be performed as routinely as one would hope or as quickly as needed in emergency situations.

\section{Impella}

The Impella (Abiomed, Danvers, MA, USA) device is a pVAD with an axial flow pump that is inserted via the femoral artery and across the aortic valve that aspirates blood from the left ventricle (Figure 4). The Impella 2.5 and Impella CP devices are inserted percutaneously and provide a cardiac output from 2.5 to $4.0 \mathrm{~L} / \mathrm{min}$. A larger device, the Impella 5.0, is able to maintain a cardiac output of $5.0 \mathrm{~L} / \mathrm{min}$ but requires a large 22-Fr sheath and cannula as well as a surgical cutdown of the femoral artery [44]. The Impella device improves hemodynamics by directly unloading the left ventricle, reducing enddiastolic wall stress and immediately decreasing pulmonary capillary wedge pressure without elevating afterload [45]. Contraindications to Impella device use include moderate to severe aortic insufficiency or aortic valve stenosis, a mechanical aortic valve, and severe peripheral arterial disease.

The Impella device was approved by the US Food and Drug Administration in 2008 on the basis of hemodynamic studies. In 2003, use of the Impella device in refractory cardiogenic shock, when added to the maximum regimens of inotropic and IABP support, showed hemodynamic improvement by increasing cardiac output and reducing pulmonary capillary wedge pressure [46]. In the Efficacy Study of LV Assist Device to Treat Patients with Cardiogenic Shock (ISAR-SHOCK), patients in cardiogenic shock were randomly assigned to either an IABP or an Impella 2.5 device. Patients who received the Impella 2.5 had significantly improved hemodynamic results compared with an IABP; however, like the TandemHeart ${ }^{\circ}$, the Impella 2.5 did not demonstrate a 30-day mortality benefit compared with the IABP [47]. The European Shock Control (EUROSHOCK) Registry trial revealed similar hemodynamic improvement in patients in refractory cardiogenic shock but again no mortality benefit, although the study was retrospective and lacked a control group [48]. One small non-randomized study comparing the Impella 5.0 with the Impella 2.5 showed a trend to improved survival in cardiogenic shock complicating STEMI with the Impella 5.0, but there was no statistical 
Figure 4. Impella 2.5

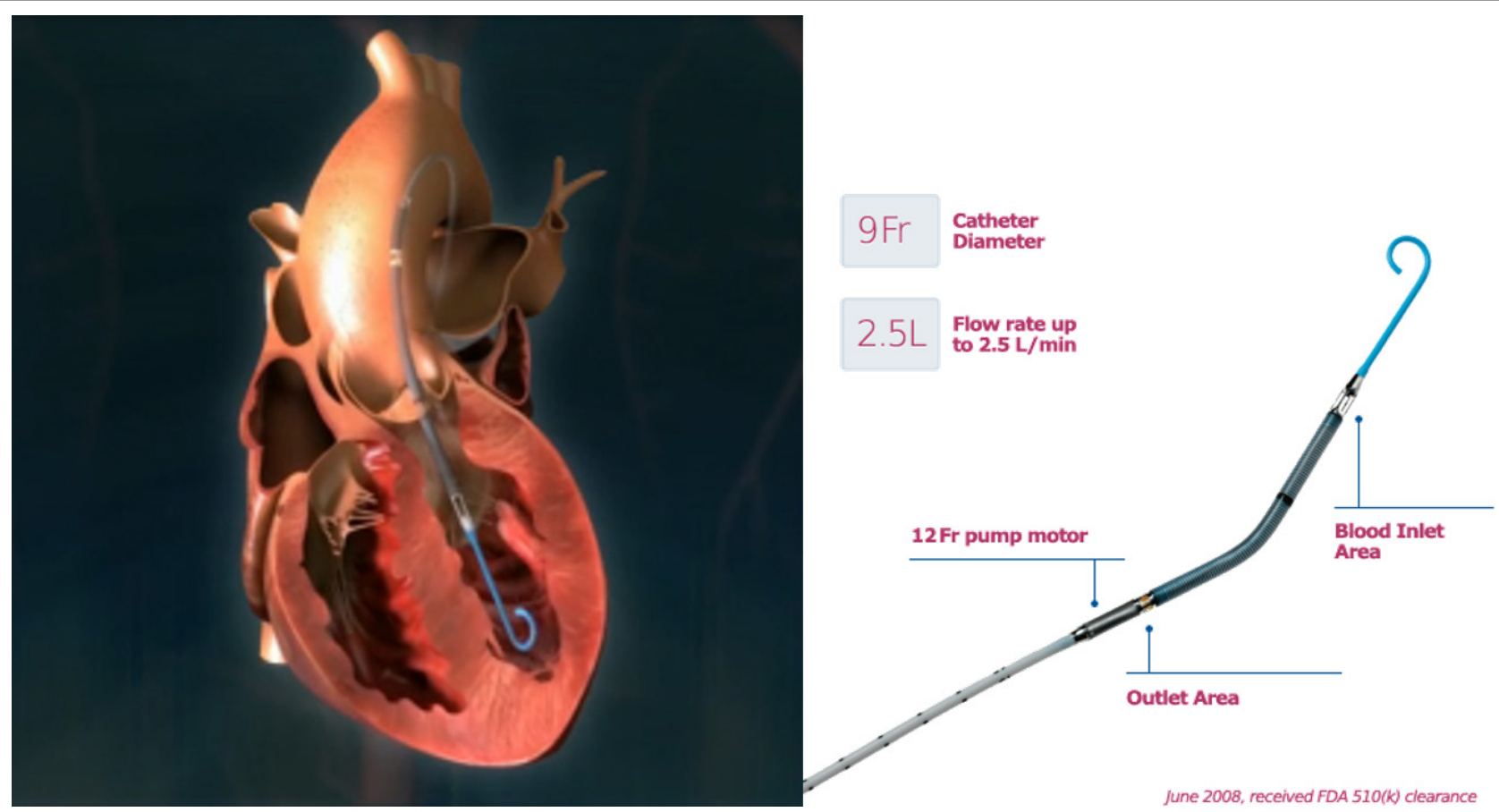

The Impella pulls blood from the left ventricle through an inlet area near the tip and expels blood from the catheter into the ascending aorta. The pump can be inserted via a standard catheterization procedure through the femoral artery, into the ascending aorta, across the valve, and into the left ventricle. Images provided with permission from Abiomed (Danvers, MA, USA).

Abbreviation: Fr, French.

Table 3. Comparison of devices

\begin{tabular}{|c|c|c|c|c|c|c|}
\hline & Impella 2.5 & Impella CP & Impella 5.0 & ECMO & TandemHeart $₫$ & IABP \\
\hline $\begin{array}{l}\text { Pump } \\
\text { mechanism } \\
\text { Cannula size }\end{array}$ & $\begin{array}{l}\text { Axial flow/ } \\
\text { Transvalvular } \\
\text { I2 Fr }\end{array}$ & $\begin{array}{l}\text { Axial flow/ } \\
\text { Transvalvular } \\
\text { I4 Fr }\end{array}$ & $\begin{array}{l}\text { Axial flow/ } \\
\text { Transvalvular } \\
\text { 2I Fr }\end{array}$ & $\begin{array}{l}\text { Centrifugal/Bypass } \\
\text { 18-2I Fr inflow } \\
\text { I5-22 Fr outflow }\end{array}$ & $\begin{array}{l}\text { Centrifugal/Bypass } \\
21 \mathrm{Fr} \text { inflow } \\
\text { 15-17 Fr outflow }\end{array}$ & $\begin{array}{l}\text { Pneumatic } \\
\text { Counterpulsation } \\
7-9 \mathrm{Fr}\end{array}$ \\
\hline $\begin{array}{l}\text { Cardiac output } \\
\text { Vascular } \\
\text { Surgery }\end{array}$ & $\begin{array}{l}2.5 \mathrm{~L} / \mathrm{min} \\
\mathrm{No}\end{array}$ & $\begin{array}{l}3.7 \mathrm{~L} / \mathrm{min} \\
\text { No }\end{array}$ & $\begin{array}{l}5.0 \mathrm{~L} / \mathrm{min} \\
\text { Yes }\end{array}$ & $\begin{array}{l}>4.5 \mathrm{~L} / \mathrm{min} \\
\text { Yes }\end{array}$ & $\begin{array}{l}4-5 \mathrm{~L} / \mathrm{min} \\
\text { No }\end{array}$ & $\begin{array}{l}0.5 \mathrm{~L} / \mathrm{min} \\
\text { No }\end{array}$ \\
\hline $\begin{array}{l}\text { Complexity of } \\
\text { Insertion }\end{array}$ & Medium & Medium & High & Medium & High & Low \\
\hline $\begin{array}{l}\text { Wall Puncture } \\
\text { Hemorrhagic } \\
\text { Complications }\end{array}$ & $\begin{array}{l}\text { No } \\
\text { Medium }\end{array}$ & $\begin{array}{l}\text { No } \\
\text { Medium }\end{array}$ & $\begin{array}{l}\text { No } \\
\text { Medium }\end{array}$ & $\begin{array}{l}\text { No } \\
\text { High }\end{array}$ & $\begin{array}{l}\text { Yes } \\
\text { High }\end{array}$ & $\begin{array}{l}\text { No } \\
\text { Low }\end{array}$ \\
\hline
\end{tabular}

Abbreviations: ECMO, extracorporeal membrane oxygenation; Fr, French; IABP, intra-aortic balloon pump.

significance and the patients were not contemporaneous [49]. In 2010, the trial using the Impella LP 2.5 system in patients with acute myocardial infarction induced hemodynamic instability (RECOVER II) and was unfortunately terminated due to the lack of power to reach its primary goal (NCT00972270). There is a paucity of data for the Impella device for acute treatment of acute MI, especially when it is complicated by cardiogenic shock. Like the TandemHeart ${ }^{\circledR}$, it is given a class IIb recommendation by the ACC/AHA but no recommendation by the ESC/
European Association for Cardio-Thoracic Surgery guidelines. Unlike the TandemHeart ${ }^{\circledR}$, we do recommend the Impella device be considered for use in preference to IABP for acute cardiogenic shock in experienced institutions (Tables 2 and 3).

\section{Conclusions}

Despite multiple medical advances, acute cardiogenic shock has a poor prognosis. Management should begin with fluid resuscitation, inotrope/vasopressor therapy, 
and, in patients with an ischemic etiology, prompt revascularization. In patients with refractory cardiogenic shock, concurrent mechanical circulatory support should also be initiated. For a long time, IABP counterpulsation was considered to have a mortality benefit until the IABP SHOCK-II trial was performed. Comparison with the other mechanical support devices has shown a hemodynamic advantage for VADs; however, a significant improvement in survival with VADs has not yet been demonstrated. We believe that the IABP should be considered the initial mechanical circulatory support device in acute cardiogenic shock because it is easy to insert. Peripheral VADs may be considered in experienced centers in preference to IABP for patients with more severe shock. Further randomized studies are needed to properly evaluate outcomes after use of mechanical support devices in cardiogenic shock and to define their most appropriate role.

\section{Abbreviations}

ACC/AHA, American College of Cardiology/American Heart Association; CI, confidence interval; ECMO, extracorporeal membrane oxygenation; ESC, European Society of Cardiology; Fr, French; IABP, intra-aortic balloon pump; LV, left ventricular; LVAD, left ventricular assist device; MCS, mechanical cardiac support; MI, myocardial infarction; NRMI-2, National Registry of Myocardial Infarction 2; PCI, percutaneous coronary intervention; pLVAD, percutaneous left ventricular assist device; pVAD, percutaneous ventricular assist device; SHOCK, Should We Emergently Revascularize Occluded Coronaries in Cardiogenic Shock?; STEMI, ST segment elevation myocardial infarction; VA, veno-arterial; VAD, ventricular assist device.

\section{Disclosures}

The authors declare that they have no disclosures.

\section{References}

I. Hollenberg SM, Kavinsky CJ, Parrillo JE: Cardiogenic shock. Ann Intern Med 1999, 131:47-59.

2. Hochman JS, Buller CE, Sleeper LA, Boland J, Dzavik V, Sanborn TA, Godfrey E, White HD, Lim J, Lejemtel T: Cardiogenic shock complicating acute myocardial infarction-etiologies, management and outcome: a report from the SHOCK Trial Registry. SHould we emergently revascularize Occluded Coronaries for cardiogenic shock? J Am Coll Cardiol 2000, 36:1063-70.

3. Goldberg RJ, Spencer FA, Gore JM, Lessard D, Yarzebski J: Thirtyyear trends (1975 to 2005) in the magnitude of, management of, and hospital death rates associated with cardiogenic shock in patients with acute myocardial infarction: a populationbased perspective. Circulation 2009, I19:1211-9.

4. Forrester JS, Diamond G, Chatterjee K, Swan HJ: Medical therapy of acute myocardial infarction by application of hemodynamic subsets (second of two parts). N Engl J Med 1976, 295: 1404-13.
5. McNulty E, Timm C: Cardiogenic Shock. In CURRENT Diagnosis \& Treatment: Cardiology. $3^{\text {rd }}$ edition. Edited by Crawford MH. New York: McGraw-Hill; 2009.

6. Gurm HS, Bates ER: Cardiogenic shock complicating myocardial infarction. Crit Care Clin 2007, 23:759-77, vi.

7. Löllgen $\mathrm{H}$, Drexler $\mathrm{H}$ : Use of inotropes in the critical care setting. Crit Care Med 1990, I8:S56-60.

8. Backer D de, Biston P, Devriendt J, Madl C, Chochrad D, Aldecoa C, Brasseur A, Defrance P, Gottignies P, Vincent J: Comparison of dopamine and norepinephrine in the treatment of shock. N Engl J Med 2010, 362:779-89.

\section{FlOOOPrime \\ RECOMMENDED}

9. Thiele H, Allam B, Chatellier G, Schuler G, Lafont A: Shock in acute myocardial infarction: the Cape Horn for trials? Eur Heart J 2010, 31:1828-35.

10. Kantrowitz A: Experimental augmentation of coronary flow by retardation of the arterial pressure pulse. Surgery 1953, 34:678-87.

II. Kantrowitz A: Origins of intraaortic balloon pumping. Ann Thorac Surg 1990, 50:672-4.

12. The New York Times: Dr Adrian Kantrowitz, Cardiac Pioneer, Dies at 90. [http://www.nytimes.com/2008// I/19/us/19kantrowiztz. html]

13. Fleisher L, Roizen MF, Windsor J: Intra-Aortic Balloon Counterpulsation (IABCP). In Essence of Anesthesia Practice: Expert Consult. $3^{\text {rd }}$ edition. Philadelphia: Saunders; 2010, 474.

14. Krishna M, Zacharowski K: Principles of intra-aortic balloon pump counterpulsation. Contin Educ Anaesth Crit Care Pain 2009, 9:24-8.

15. O'Rourke MF, Norris RM, Campbell TJ, Chang VP, Sammel NL: Randomized controlled trial of intraaortic balloon counterpulsation in early myocardial infarction with acute heart failure. Am J Cardiol 1981, 47:815-20.

16. Flaherty JT, Becker LC, Weiss JL, Brinker JA, Bulkley BH, Gerstenblith G, Kallman CH, Weisfeldt ML: Results of a randomized prospective trial of intraaortic balloon counterpulsation and intravenous nitroglycerin in patients with acute myocardial infarction. I Am Coll Cardiol 1985, 6:434-46.

17. Anderson RD, Ohman EM, Holmes DR, Col I, Stebbins AL, Bates ER, Stomel RJ, Granger CB, Topol EJ, Califf RM: Use of intraaortic balloon counterpulsation in patients presenting with cardiogenic shock: observations from the GUSTO-I Study. Global Utilization of Streptokinase and TPA for Occluded Coronary Arteries. J Am Coll Cardiol 1997, 30:708-I5.

18. Kovack PJ, Rasak MA, Bates ER, Ohman EM, Stomel RJ: Thrombolysis plus aortic counterpulsation: improved survival in patients who present to community hospitals with cardiogenic shock. J Am Coll Cardiol 1997, 29: 1454-8.

19. Sanborn TA, Sleeper LA, Bates ER, Jacobs AK, Boland J, French JK, Dens J, Dzavik V, Palmeri ST, Webb JG, Goldberger M, Hochman JS: Impact of thrombolysis, intra-aortic balloon pump counterpulsation, and their combination in cardiogenic shock complicating acute myocardial infarction: a report from the SHOCK Trial Registry. SHould we emergently revascularize Occluded Coronaries for cardiogenic shocK? J Am Coll Cardiol 2000, 36: II 23-9.

20. Barron HV, Every NR, Parsons LS, Angeja B, Goldberg RJ, Gore JM, Chou TM: The use of intra-aortic balloon counterpulsation in patients with cardiogenic shock complicating acute myocardial infarction: data from the National Registry of Myocardial Infarction 2. Am Heart J 200I, 141:933-9.

21. Sjauw KD, Engström AE, Vis MM, van der Schaaf, René J, Baan J, Koch KT, de Winter, Robbert J, Piek JJ, Tijssen, Jan G P, Henriques, José P S: A systematic review and meta-analysis of intra-aortic balloon pump therapy in ST-elevation myocardial infarction: should we change the guidelines? Eur Heart J 2009, 30:459-68.

22. Prondzinsky $R$, Lemm $H$, Swyter $M$, Wegener $N$, Unverzagt $S$, Carter JM, Russ M, Schlitt A, Buerke U, Christoph A, Schmidt H, 
Winkler M, Thiery J, Werdan K, Buerke M: Intra-aortic balloon counterpulsation in patients with acute myocardial infarction complicated by cardiogenic shock: the prospective, randomized IABP SHOCK Trial for attenuation of multiorgan dysfunction syndrome. Crit Care Med 2010, 38:152-60.

23. Thiele H, Zeymer U, Neumann F, Ferenc M, Olbrich H, Hausleiter J, Richardt G, Hennersdorf M, Empen K, Fuernau G, Desch S, Eitel I, Hambrecht R, Fuhrmann J, Böhm M, Ebelt H, Schneider S, Schuler G, Werdan K: Intraaortic balloon support for myocardial infarction with cardiogenic shock. $N$ Engl J Med 20I2, 367:1287-96.

\section{FIOOOPrime
RECOMMENDED}

24. Thiele H, Zeymer U, Neumann F, Ferenc M, Olbrich H, Hausleiter J, Waha A de, Richardt G, Hennersdorf M, Empen K, Fuernau G, Desch S, Eitel I, Hambrecht R, Lauer B, Böhm M, Ebelt H, Schneider S, Werdan K, Schuler G: Intra-aortic balloon counterpulsation in acute myocardial infarction complicated by cardiogenic shock (IABP-SHOCK II): final 12 month results of a randomised, open-label trial. Lancet 2013, 382:1638-45.

\section{FlOOOPrime}

25. Anderson JL, Adams CD, Antman EM, Bridges CR, Califf RM, Casey DE, Chavey WE, Fesmire FM, Hochman JS, Levin TN, Lincoff AM, Peterson ED, Theroux P, Wenger NK, Wright RS, Smith SC: 20II ACCF/AHA Focused Update Incorporated Into the ACC/ AHA 2007 Guidelines for the Management of Patients With Unstable Angina/Non-ST-Elevation Myocardial Infarction: a report of the American College of Cardiology Foundation/ American Heart Association Task Force on Practice Guidelines. Circulation 20I I, I 23:e426-579.

26. Steg PG, James SK, Atar D, Badano LP, Blömstrom-Lundqvist C, Borger MA, Di Mario C, Dickstein K, Ducroca G, Fernandez-Aviles F, Gershlick AH, Giannuzzi P, Halvorsen S, Huber K, Juni P, Kastrati A, Knuuti J, Lenzen MJ, Mahaffey KW, Valgimigli M, van't Hof, Arnoud, Widimsky P, Zahger D: ESC Guidelines for the management of acute myocardial infarction in patients presenting with STsegment elevation. Eur Heart J 2012, 33:2569-619.

27. Daily PO, Johnston GG, Simmons CJ, Moser KM: Surgical management of chronic pulmonary embolism: surgical treatment and late results. J Thorac Cardiovasc Surg 1980, 79:523-3I.

28. Kinsella JP, Gerstmann DR, Rosenberg AA: The effect of extracorporeal membrane oxygenation on coronary perfusion and regional blood flow distribution. Pediatr Res 1992, 31:80-4.

29. Koenig PR, Ralston MA, Kimball TR, Meyer RA, Daniels SR, Schwartz DC: Balloon atrial septostomy for left ventricular decompression in patients receiving extracorporeal membrane oxygenation for myocardial failure. J Pediatr 1993, I 22:S95-9.

30. Hill JD, O'Brien TG, Murray JJ, Dontigny L, Bramson ML, Osborn JJ, Gerbode F: Prolonged extracorporeal oxygenation for acute post-traumatic respiratory failure (shock-lung syndrome). Use of the Bramson membrane lung. $N$ Engl J Med 1972, 286:629-34

31. Lafç G, Budak AB, Yener AÜ, Cicek OF: Use of extracorporeal membrane oxygenation in adults. Heart Lung Circ 2014, 23:10-23.

32. Smedira NG, Moazami N, Golding CM, McCarthy PM, AppersonHansen C, Blackstone EH, Cosgrove DM: Clinical experience with 202 adults receiving extracorporeal membrane oxygenation for cardiac failure: survival at five years. J Thorac Cardiovasc Surg 200I, I22:92-102.

33. Combes A, Leprince P, Luyt C, Bonnet N, Trouillet J, Léger P, Pavie A, Chastre J: Outcomes and long-term quality-of-life of patients supported by extracorporeal membrane oxygenation for refractory cardiogenic shock. Crit Care Med 2008, 36: I404-II.

34. Formica F, Avalli L, Martino A, Maggioni E, Muratore M, Ferro O, Pesenti A, Paolini G: Extracorporeal membrane oxygenation with a poly-methylpentene oxygenator (Quadrox D). The experience of a single Italian centre in adult patients with refractory cardiogenic shock. ASAIO J 2008, 54:89-94.
35. Tsao N, Shih C, Yeh J, Kao Y, Hsieh M, Ou K, Chen J, Shyu K, Weng Z, Chang N, Lin F, Huang C: Extracorporeal membrane oxygenation-assisted primary percutaneous coronary intervention may improve survival of patients with acute myocardial infarction complicated by profound cardiogenic shock. J Crit Care 2012, 27:530.el-II.

36. Paden ML, Conrad SA, Rycus PT, Thiagarajan RR: Extracorporeal Life Support Organization Registry Report 20I2. ASAIO J 20I3, 59:202-10.

37. DeBakey ME: Left ventricular bypass pump for cardiac assistance. Clinical experience. Am J Cardiol I97I, 27:3-II.

38. Givertz MM: Cardiology patient pages: ventricular assist devices: important information for patients and families. Circulation 20II, I24:e305-II.

39. McCulloch B: Use of the Impella 2.5 in high-risk percutaneous coronary intervention. Crit Care Nurse 201I, 3I:el-16.

40. Vranckx P, Foley DP, de Feijter, Pim J, Vos J, Smits P, Serruys PW: Clinical introduction of the Tandemheart, a percutaneous left ventricular assist device, for circulatory support during high-risk percutaneous coronary intervention. Int J Cardiovasc Intervent 2003, 5:35-9.

4I. Thiele H, Sick P, Boudriot E, Diederich K, Hambrecht R, Niebauer J, Schuler G: Randomized comparison of intra-aortic balloon support with a percutaneous left ventricular assist device in patients with revascularized acute myocardial infarction complicated by cardiogenic shock. Eur Heart J 2005, 26:1276-83.

42. Burkhoff $D$, Cohen $H$, Brunckhorst $C$, O'Neill WW: A randomized multicenter clinical study to evaluate the safety and efficacy of the TandemHeart percutaneous ventricular assist device versus conventional therapy with intraaortic balloon pumping for treatment of cardiogenic shock. Am Heart J 2006, 152:469.el-8.

43. Kar B, Gregoric ID, Basra SS, Idelchik GM, Loyalka P: The percutaneous ventricular assist device in severe refractory cardiogenic shock. J Am Coll Cardiol 20II, 57:688-96.

44. Henriques, José $P$ S, Remmelink M, Baan J, van der Schaaf, René J, Vis MM, Koch KT, Scholten EW, de Mol, Bas A J M, Tijssen, Jan G P, Piek JJ, de Winter, Robbert J: Safety and feasibility of elective high-risk percutaneous coronary intervention procedures with left ventricular support of the Impella Recover LP 2.5. Am J Cardiol 2006, 97:990-2.

45. Meyns B, Dens J, Sergeant P, Herijgers P, Daenen W, Flameng W: Initial experiences with the Impella device in patients with cardiogenic shock - Impella support for cardiogenic shock. Thorac Cardiovasc Surg 2003, 51 : 312-7.

46. Engström AE, Cocchieri R, Driessen AH, Sjauw KD, Vis MM, Baan J, Jong M de, Lagrand WK, van der Sloot, Jos A P, Tijssen JG, de Winter, Robbert J, de Mol, Bas A S, Piek JJ, Henriques, José P J M: The Impella 2.5 and $\mathbf{5 . 0}$ devices for ST-elevation myocardial infarction patients presenting with severe and profound cardiogenic shock: the Academic Medical Center intensive care unit experience. Crit Care Med 201 I, 39:2072-9.

47. Seyfarth M, Sibbing D, Bauer I, Fröhlich G, Bott-Flügel L, Byrne R, Dirschinger J, Kastrati A, Schömig A: A randomized clinical trial to evaluate the safety and efficacy of a percutaneous left ventricular assist device versus intra-aortic balloon pumping for treatment of cardiogenic shock caused by myocardial infarction. J Am Coll Cardiol 2008, 52:1584-8.

\section{FlOOOPrime}

RECOMMENDED

48. Lauten $A$, Engström $A E$, Jung $C$, Empen $K$, Erne $P$, Cook $S$, Windecker S, Bergmann MW, Klingenberg R, Lüscher TF, Haude M, Rulands D, Butter C, Ullman B, Hellgren L, Modena MG, Pedrazzini G, Henriques, Jose P S, Figulla HR, Ferrari M: Percutaneous leftventricular support with the Impella-2.5-assist device in acute cardiogenic shock: results of the Impella-EUROSHOCKregistry. Circ Heart Fail 20I3, 6:23-30. 
49. Dixon SR, Henriques, José P S, Mauri L, Sjauw K, Civitello A, Kar B, Loyalka P, Resnic FS, Teirstein P, Makkar R, Palacios IF, Collins M, Moses J, Benali K, O'Neill WW: A prospective feasibility trial investigating the use of the Impella 2.5 system in patients undergoing high-risk percutaneous coronary intervention (The PROTECT I Trial): initial U.S. experience. JACC Cardiovasc Interv 2009, 2:91-6.

50. Scheidt $S$, Wilner $G$, Mueller $H$, Summers $D$, Lesch $M$, Wolff $G$, Krakauer J, Rubenfire M, Fleming P, Noon G, Oldham N, Killip T, Kantrowitz A: Intra-aortic balloon counterpulsation in cardiogenic shock-Report of a co-operative clinical trial. N Engl J Med 1973, 288:979-84.
5I. Chauhan S, Subin S: Extracorporeal membrane oxygenation, an anesthesiologist's perspective: Physiology and principles: Part I. Ann Card Anaesth 2011, 14:218-29.

52. Weber DM, Raess DH, Henriques J, Siess T: Principles of Impella Cardiac Support. Cardiac Interventions Today, August/September 2009, 3-16.

53. Nathan S: Hemodynamic Support in Myocardial Infarction-related Cardiogenic Shock. American College of Osteopathic Internists (ACOI) Convention; 2013. [http://www.acoi.org/20I3Convention/ Sandeep2.pdf] 